\title{
Rede de Formação e Desenvolvimento Profissional e Constituição de Comunidade: um diálogo sobre o percurso formativo inicial docente em educação a distância
}

\author{
Andriza Machado Becker ${ }^{1}$ - UFSM - andrizabecker@gmail.com
}

\section{RESUMO}

Na modalidade de Educação a Distância (EAD) desenvolvem-se relações didáticas, pedagógicas e interpessoais potencialmente propícias à formação de redes de formação e desenvolvimento profissional que, por sua vez, podem conduzir à constituição de comunidade. Remetendo-se ao percurso formativo inicial docente, como a trajetória de formação nos grupos que são significativos ao professor, enquanto pessoa/profissional, foi realizada uma pesquisa de abordagem qualitativa com os primeiros formandos do Curso de Letras/Espanhol e Literaturas EAD/UAB/UFSM. Neste estudo, identificou-se características de uma rede de formação e desenvolvimento profissional, especialmente no que tange à capacitação em formação para a integração das Tecnologias da Informação e Comunicação (TIC) ao ensino. Em relação à constituição de comunidade, não foi possível inferir indicadores solidificados. No entanto, há elementos significativos no percurso formativo que, se reforçados, podem despertar 0 pertencimento e engajamento a um grupo formativo.

Palavras-chave: Rede de Formação e Desenvolvimento Profissional. Comunidade. Percurso Formativo. Formação de Professores. EAD.

Training and Professional Development Network and Constitution of Community: a dialogue on the initial teacher training course in distance education

\begin{abstract}
In the mode of distance education (EAD) develop didactic, pedagogical relationships and potentially conducive to interpersonal networking of training and professional development that, in turn, can lead to the formation of the community. Referring to the initial teacher training course, as the trajectory of training in groups that are significant to the teacher, while person/professional, a qualitative research with the first graduates of the course Spanish and Literature/EAD/UAB/UFSM. In this study, identified characteristics of a network of training and professional development, especially with respect to training training for the integration of information and communication technologies (ICT) in education. On the Constitution of the community, it has not been possible to infer solidified indicators. However, there are significant elements in the training course which, if strengthened, can awaken the belonging and engagement to a training group.
\end{abstract}

Keywords: Network of training and Professional Development. Community. Formative Journey. Teacher training. EAD.

\footnotetext{
${ }^{1}$ Mestranda do Curso de Pós-Graduação em Educação - PPGE/UFSM. Especialista em TIC Aplicadas à Educação e Professora Tutora do Curso de Letras/Espanhol EAD/UAB/UFSM.
}

V. $11 \mathrm{~N}^{\circ} 1$, julho, 2013 


\section{INICIANDO O DIÁLOGO - o cenário da EAD na perspectiva da trajetória de formação construída}

Desde a criação da Universidade Aberta do Brasil (UAB), em 2005, em sua grande maioria, os cursos ofertados na modalidade EAD são voltados à formação de professores. A modalidade vem apresentando evidente crescimento nas Instituições de Ensino Superior (IES) brasileiras. No âmbito da UFSM, por exemplo, há atualmente 4.309 alunos matriculados em cursos dos níveis pós-médio, graduação e pós-graduação, representando um percentual de 15,62\% do total de alunos matriculados na instituição.

Os cursos EAD agregam um grande número de participantes nos AVEA (estudantes, professores e tutores) e também na sua organização de apoio estrutural (polos e coordenação). Por esta razão podem contribuir para a formação de redes de formação e desenvolvimento profissional, as quais podem conduzir à constituição de comunidades - experiências formativas que tendem a favorecer a construção colaborativa do conhecimento, bem como fortalecer grupos de professores em formação, na esfera pessoal e profissional.

Francesc Imbérnon (2009) enfatiza que "tenemos un modelo escolar del siglo XIX, profesores del siglo XX y alumnos del siglo XXI, ésta es una combinación muy peligrosa”. Nesta direção, pode-se inferir que o professorado atual é moderno, porém os alunos são pós-modernos e esta ambivalência provoca um desencontro entre ambos. Da mesma forma, poderão ser observados tantos outros desencontros históricos, sociais e culturais nos ambientes escolares e na própria formação docente.

Para o autor a formação docente é um processo contínuo de desenvolvimento profissional, termo empregado por Garcia (1999) em substituição à formação inicial e continuada, que abrange diferentes fatores e espaços como: salário, estruturas hierárquicas, condições de trabalho e incidindo no nível individual e coletivo do professor enquanto pessoa.

O ciberespaço, termo definido por Lévy (2000) como a instauração de uma rede informatizada que abriga um novo espaço de interação humana que já tem importância nos planos econômicos e científicos podendo se ampliar a vários outros campos, apresenta possibilidades para a formação de professores em diferentes níveis de ensino. Sendo assim, é interessante refletir e problematizar como esse novo cenário virtual de formação, apoiado pelo uso de Tecnologias da Informação e Comunicação (TIC), pode contribuir para a capacitação de professores às demandas do ensino contemporâneo, bem como quais são os elementos mais significativos neste percurso formativo.

Entende-se por percurso formativo a articulação do conceito de 'percurso vital', proposto por Maciel (2000), ao conceito de 'trajetórias de formação', proposto por Isaia (2006). Tais conceitos imbricam-se na abordagem do professor como pessoa/profissional em espaços formativos, nos quais o "professor se reconhece, formando-se e transformando-se em interação com grupos que lhe são significativos, sejam estes formados por colegas, alunos ou demais integrantes da comunidade educativa” (ISAIA, 2006, p. 368). O percurso formativo, portanto, é um continuum iniciado desde a opção pela profissão e perpassa a formação inicial, os primeiros espaços de atuação profissional e outros movimentos de construção da docência.

Neste artigo, será apresentado um recorte da pesquisa intitulada "Constituição de Comunidade: [im] possibilidades no percurso formativo em EAD” a qual teve como objetivo geral investigar o percurso formativo inicial docente dos primeiros formandos do Curso de Letras/Espanhol e Literaturas EAD/UAB/UFSM no sentido de compreender como se constitui (ou não) uma comunidade. Para tanto, os objetivos específicos propostos, delimitam a abordagem de pesquisa em: (1) conhecer o perfil dos 
estudantes da primeira turma do Curso de Letras/Espanhol e Literaturas EAD/UAB/UFSM; (2) descrever suas concepções a respeito da modalidade EAD e suas relações didático-pedagógicas no âmbito do curso; (3) destacar, no seu percurso formativo inicial, elementos que foram significativos em sua trajetória de formação; (4) buscar características que possam configurar a formação de rede de formação e desenvolvimento profissional colaborativa no âmbito do curso e (5) inferir a existência ou não de fatores indicativos de constituição de comunidade.

\section{O PERCURSO FORMATIVO EM EAD: PERCEPÇÕES E PERSPECTIVAS}

Ao lançar o olhar para a inserção da EAD na perspectiva da expansão e interiorização do ensino superior público e gratuito, observa-se com destaque que as iniciativas são voltadas à formação de professores, seja inicial ou continuada, pois "embora a UAB não ofereça apenas cursos para a formação de professores, ela demonstra a sua prioridade, pois $72 \%$ de suas graduações são licenciaturas, sendo o restante dividido entre bacharelados (23,5\%) e tecnólogos (4,4\%)" (SARAIVA, 2010, p. 125).

Essa realidade reforça a construção de novas trajetórias de formação e a atribuição de novos sentidos e significados ao percurso formativo e ao desenvolvimento profissional docente, pois as motivações que levam à escolha da profissão perpassam também pela [des] construção do aprender e ensinar a partir de lugares estáticos e delimitados.

Faz-se necessário destacar que a EAD, enquanto modalidade de ensino que utiliza variadas tecnologias para a planificação, aprendizagem e comunicação, proporciona ao professor em formação a vantagem de estar recebendo a capacitação para o uso das TIC no ensino já inserida em seu percurso formativo inicial. Esse processo tende a ser construído por meio de uma rede de formação colaborativa que agrega vários participantes: a própria UAB, enquanto instituição promotora da modalidade EAD, suas parceiras (as IES públicas), viabilizadoras de espaços físicos e virtuais de formação, os professores que planificam a aprendizagem, os tutores que realizam a mediação pedagógica e os estudantes em situação de formação.

\subsection{Rede de Formação e Desenvolvimento Profissional}

Na concepção de Moran (2005), a internet é uma grande rede que dissemina muita informação e possibilidades de aprendizagem, portanto, vem provocando mudanças profundas na educação. O próprio conceito de rede, enquanto espaço de integração e compartilhamento, desenraiza o conceito de ensino-aprendizagem localizado e temporalizado no qual historicamente os pressupostos da educação presencial residem. Da mesma forma, o surgimento e reconhecimento da educação virtual agrega uma nova visão de aprendizagem que pode alternar formas individuais e coletivas para a construção do conhecimento.

Estar interligado em rede pressupõe a existência de uma ligação comum entre os que nela estão envolvidos. No caso de um curso EAD, o ambiente virtual pode gerar essa potencialidade agregadora, uma vez que é o ponto de chegada e de partida para diferentes ações didático-pedagógicas ou institucionais, agregando também diferentes sujeitos com diferentes papeis (professor, tutor, coordenação, suporte). 
Uma rede virtual de formação constitui-se em um "espaço propício ao desenvolvimento profissional docente envolvendo o processo formativo dos professores e viabilizando novos modos de aprendizagem docente” (MACIEL, 2006, pp. 380-81).

$\mathrm{Na}$ formação docente mediada por tecnologias, a construção de uma rede de formação e desenvolvimento profissional colaborativa se traduz como a malha tecida entre os colaboradores envolvidos na estrutura de um curso EAD. Neste caso, trata-se de uma rede institucionalizada que depende da participação multidirecional para a viabilidade de seus propósitos.

Diante deste cenário formativo promissor em que interagem vários sujeitos, a rede de formação colaborativa estabelecida em um curso EAD voltado à formação de professores poderá, supõe-se, constituir também uma comunidade; enquanto convergência dessa rede em grupo(s) constituído(s) durante a trajetória de formação.

\subsection{Comunidade: [des] construindo a palavra e o conceito}

A palavra comunidade deriva do latim communis, que significa "comum, partilhado por muitos ou todos, público”. Diante da etimologia e da semântica da palavra, percebe-se que seu significado e contexto de uso são assinalados por fatores sociais, históricos, culturais, ideológicos, econômicos e biológicos, sendo possível a existência de variados tipos de comunidades nas quais os participantes estão inseridos de maneira voluntária ou por outros fatores condicionantes.

Geralmente, uma das primeiras experiências que o ser humano vivencia em comunidade refere-se ao espaço de convívio familiar, pois é a referência primeira de compartilhamento, de espaço comum. Sob esta mesma ótica, a experiência vai se ampliando nas comunidades de bairro, no espaço escolar e em diversos outros espaços em que está presente o sentimento de pertencimento em algum dado momento.

Os estudos envolvendo o termo comunidade, como espaço de diferentes relações dentro da sociedade, tiveram emergência no final do século XIX e início do século XX. A noção mais recente de comunidade surge por meio de estudos que levantam à fragmentação das relações humanas e a dificuldade de encontrar 'lugares' de identificação e pertencimento.

Para o sociólogo Zygmunt Bauman, os laços humanos encontram-se completamente fragilizados e, assim, as noções de pertencimento e comunidade estão em constante mudança. Vivemos em uma "modernidade-líquida" - o autor utiliza termos designadores dos estados físicos da matéria (líquido, sólido e gasoso) para estabelecer analogia com a temporalidade, a forma e a instantaneidade com as quais os sujeitos moldam-se em relação a infinitas estruturas, nas quais as dissoluções dos laços afetivos e sociais são o centro da questão.

Pertencer a uma comunidade agrega sempre um sentimento bom, pois remete a um local de segurança, compreensão, empatia. “Comunidade produz uma sensação boa em virtude dos significados que a palavra carrega” (BAUMAN, 2003, p.7). Ou seja, comunidade sempre remete a um ponto comum, de partilha, um lugar confortável e aconchegante.

No entanto, com o 'derretimento' dos sólidos da Modernidade, as formas de se relacionar com o outro se tornaram mais instáveis do que nunca; não só é difícil constituir uma comunidade, mas manter-se nela e preservá-la. 


\title{
2.3 Constituição de Comunidades Virtuais
}

Howard Rheingold (1996) foi um dos pioneiros a conceitualizar o termo comunidade virtual, impulsionado pela experiência própria de participante ativo há mais de uma década na WELL (Whole Earth Lectronic Link): "sistema de teleconferência por computador que permite aos participantes espalhados pelo globo a participação em conversas públicas e a troca de correspondência privada via correio eletrônico" (RHEINGOLD, 1996, p. 13).

As considerações tecidas pelo autor constituem marco importante de uma nova cultura que incidiu em vários estudos que tratam das relações tecidas no ciberespaço, incluindo o campo da educação, pois as "comunidades virtuais são lugares onde as pessoas se encontram, mas também um meio para atingir diversos fins” (RHEINGOLD, 1996, p. 76).

A constituição de uma comunidade virtual não é um ato deliberado, bem como não existem regras gerais para sua existência, como assinala o autor:

\begin{abstract}
As comunidades virtuais - uma experiência social não planejada - são os agregados sociais surgidos na Rede, quando os intervenientes de um debate o levam por diante em número e sentimento suficientes para formarem teias de relações pessoais no ciberespaço (espaço conceptual onde se manifestam palavras, relações humanas, dados, riqueza e poder dos utilizadores da tecnologia de CMC) (RHEINGOLD, 1996, p.18).
\end{abstract}

As comunidades virtuais devem ser discutidas, pensadas e identificadas a partir do locus onde se estabelecem. Assim, ao buscar elementos significativos no percurso formativo inicial em EAD, estará sendo mapeada aí a existência de uma comunidade constituída em torno de um processo educativo; podendo envolver a totalidade de participantes de um curso ou a segregação de alguns membros que estabeleceram entre si laços mais fortes e colaboração mútua.

Neste sentido, uma comunidade virtual é ponto de aproximação e manutenção de um grupo que nela está inserido por haver um sentimento de pertencimento que nutre a continuidade da participação.

Recuperando o sentido de comunidade, enquanto grupo que partilha os mesmos propósitos, Pallof e Pratt (2002) enfatizam que a formação de comunidades é um processo inerente à própria comunicação humana e que as tecnologias reforçam essa ideia.

Por esta razão, frequentemente encontra-se, nos estudos que tratam sobre comunidades virtuais, a afirmação de que ambientes virtuais de ensino-aprendizagem são propícios à constituição de comunidades, por serem ambientes que agregam um grande número de participantes, sendo assim, natural a necessidade de comunicação. Ainda assim, é preciso assinalar que somente o fato de sujeitos estarem conectados em um mesmo AVEA não é prerrogativa para que haja uma comunidade, visto que esta organização virtual implica em elementos indicadores, relacionados a diferentes aspectos de relacionamento entre seus membros.

Carvalho (2011) trata das categorias redes virtuais e comunidades virtuais, concebendo a rede como um espaço que é estabelecido anterior à comunidade que, por sua vez, seria um processo mais complexo e dependente de indicadores. Dessa forma, infere-se que uma rede de formação se constitui anterior a uma comunidade virtual de aprendizagem, assim como uma rede social vem antes da comunidade virtual.

Diferentemente de uma rede, em que se observa a interligação de participantes ou de um grupo, ligados pelo envolvimento em comum em algum espaço, na 
comunidade todos estes sujeitos estariam estreitamente entrelaçados e partilhando dos mesmos propósitos, assim pertencendo a um mesmo grupo.

No estudo desenvolvido por Carvalho (2011), no qual a autora atuou como observadora-participante de uma comunidade virtual foram formulados seis elementos indicadores de formação de comunidade em situação de aprendizagem, sendo eles:

(1) Reciprocidade Permanente - é um dos principais indícios de formação de uma comunidade virtual e refere-se à correspondência mútua, a comunicação que se estabelece permanentemente entre os participantes da comunidade (enquanto ela existir).

(2) Colaboração - havendo a reciprocidade, a colaboração surge como consequência. Neste sentido, em uma dimensão filosófica mais ampla em que as ações dos participantes sejam realizadas em conjunto, com o envolvimento deles em todo o processo.

(3) Compromisso Implícito - seguindo um raciocínio vertical em relação aos indicadores já apresentados, o compromisso diz respeito ao comprometimento que os pares assumem, tacitamente, em se corresponder com o outro, em responder às necessidades, em não deixá-los “abandonados” em ambiente virtual.

(4) Iniciativa - refere-se à predisposição em contribuir com os propósitos da comunidade, sendo assim, os indicadores levantados dependem desta iniciativa que parte, individualmente, de cada participante.

(5) Informalidade - é a utilização de uma linguagem despojada, muitas vezes com o uso de emotions ou outros recursos de escrita online que expressem o sentimento do ato comunicativo.

(6) Intervenção pontual do educador - quando da existência concreta da reciprocidade, colaboração, iniciativa e compromisso implícito entre os participantes, a participação do educador se dá num nível de supervisão e intervenção ocorre somente quando necessária.

Destaca-se que, neste estudo, a comunidade a que se refere foi um curso intitulado "Ensinando em Ambientes Virtuais 1" (EAV1), oferecido pelo Programa de Pós-Graduação da Faculdade de Educação da Universidade de São Paulo, ministrado pela professora Vani Moreira Kenski, desenvolvido em um período de três meses, com 31 participantes.

\section{DESIGN E DESENVOLVIMENTO DA PESQUISA}

Levando-se em consideração a experiência dos sujeitos e da pesquisadora, trazendo à tona o espaço comum partilhado e verificando como essas experiências foram [re] significadas no contexto da formação de professores na modalidade EAD, a pesquisa iniciou com um mapeamento exploratório. Este objetivou um contato inicial com os 78 estudantes da primeira turma do Curso de Letras/Espanhol EAD/UAB/UFSM, por meio de um questionário online composto por 37 questões. Essas questões foram subdivididas em três partes:

- I Perfil Sócio-Demográfico: questões que buscaram conhecer o perfil dos estudantes no sentido social (faixa etária, sexo, atuação profissional e formação profissional, bem como a forma de acesso à internet) e no sentido demográfico (residência e localização em relação ao polo ao qual pertencia). 
- II Relações com a EAD: questões que pretendiam descrever as experiências prévias dos estudantes com a modalidade EAD, bem como suas motivações para inserção na mesma.

- III Atividades didático-pedagógicas no curso: questões que objetivaram compreender a dinâmica de atividades dos estudantes no curso, tanto no nível de relações interpessoais (entre colegas, professores e tutores), como no nível das relações didáticas no AVEA e no polo (forma de realização de atividades, frequência de acesso ao polo e engajamentos em ações no mesmo).

O questionário foi confeccionado na ferramenta gogle docs - formulário e enviado por e-mail aos sujeitos da pesquisa, no mês de novembro de 2011, quando estavam matriculados no $6^{\circ}$ semestre letivo do curso. O índice de retorno foi de $51,3 \%$ respondentes, ou seja, dentre os 78 estudantes que receberam o questionário, 40 responderam-no.

A segunda etapa de coleta de dados, proposta no escopo desta pesquisa, foi a realização de entrevistas narrativas com seis estudantes, ou seja, uma amostra de $15 \%$ do total de participantes da etapa exploratória. Estas foram desenvolvidas nos meses de novembro e dezembro de 2012, quando os estudantes estavam em fase de conclusão do $8^{\circ}$ e último semestre letivo do curso.

Nesta pesquisa, portanto, foram propostos dois instrumentos de coleta de dados: questionário e entrevistas narrativas. Como o primeiro refere-se a uma etapa exploratória, permitindo verificar inferências para a construção de tópicos-guia para a viabilização do segundo, ambos conectam-se em um continuum que visa à mobilização e sensibilização de experiências dos sujeitos participantes.

Dentro desta perspectiva, a técnica interpretativa utilizada foi a Análise de Conteúdo (AC), proposta por Bardin (1977), na qual as recorrências textuais, nas mesmas categorias ou em categorias diferentes, têm papel de destaque como inferências no processo de interpretação.

Assim, a partir das questões que mais se destacaram na aplicação do instrumento exploratório, ou seja, àquelas que permitiram inferências a respeito do percurso formativo inicial dos sujeitos da pesquisa, foram projetadas categorias para a realização das entrevistas narrativas, as quais, no âmbito desta pesquisa, são intituladas como tópicos-guia.

\begin{tabular}{|c|c|}
\hline $\begin{array}{c}\text { ETAPA EXPLORATÓRIA } \\
\text { - Inferências - }\end{array}$ & $\begin{array}{l}\text { ENTREVISTAS NARRATIVAS } \\
\text {-Tópicos-guia- }\end{array}$ \\
\hline $\begin{array}{l}\text { I Perfil Sócio-Demográfico: } \\
\text { Identificação do perfil típico do aluno EAD }\end{array}$ & A) Inserção e Vivência na Modalidade EAD \\
\hline $\begin{array}{l}\text { II Relações com a EAD: } \\
\text { Singularidade da experiência na modalidade } \\
\text { EAD }\end{array}$ & $\begin{array}{l}\text { B) Elementos Significativos do Percurso } \\
\text { Formativo }\end{array}$ \\
\hline $\begin{array}{l}\text { III Atividades didático-pedagógicas no curso: } \\
\text { Indicativos de desenvolvimento interrelacional } \\
\text { no âmbito do polo }\end{array}$ & $\begin{array}{l}\text { C) Rede de Formação e Desenvolvimento } \\
\text { Profissional na Formação Docente em EAD }\end{array}$ \\
\hline
\end{tabular}

Figura 1 - Projeção dos tópicos-guia

De acordo com Bardin (1977), “a inferência é o procedimento intermediário, que vem permitir a passagem, explícita e controlada, de uma (etapa) à outra” (p.39). Neste sentido, as inferências passaram aos tópicos-guia e estes representaram o ponto de partida para a tessitura do diálogo, incitando à construção dos registros narrativos dos participantes da pesquisa.

O foco central passou à identificação de elementos que foram significativos na trajetória de formação, buscando assim características configurativas da formação de 
uma rede de formação e desenvolvimento profissional colaborativa no âmbito do curso e a partir disto, inferir a existência (ou não) de fatores indicativos da constituição de comunidade.

Com a construção dos registros narrativos, com seis sujeitos, emergiram então sub-tópicos, os quais surgiram a partir dos destaques narrativos sobre a experiência formativa destes sujeitos:

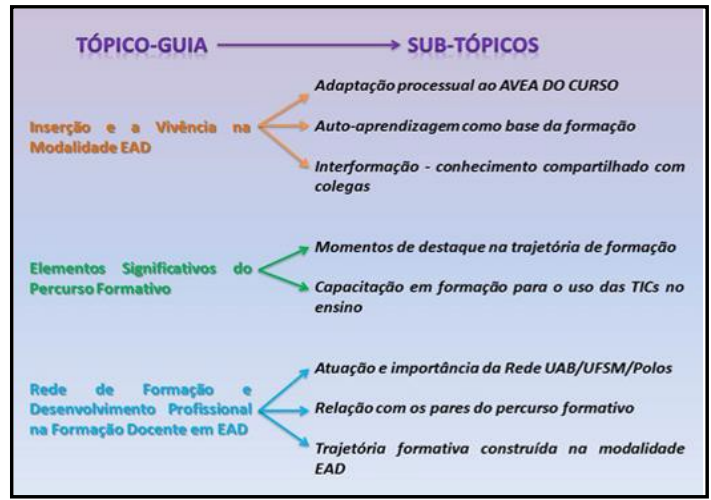

Figura 2 - Tópicos-guia e Sub-tópicos

Esta pesquisa, de natureza qualitativa, buscou a construção de significados, por meio da investigação da trajetória de formação docente de sujeitos em interações situacionais, que constituíram um percurso formativo ímpar. Portanto, entende-se como inadequado, neste contexto, apresentar conclusões a respeito de um estudo que teve como escopo mobilizar as experiências formativas de uma modalidade recentemente reconhecida e amparada pelas políticas públicas.

Nesta direção, na última seção são tecidas algumas considerações sobre os limites, possibilidades e desafios da constituição de comunidade no percurso formativo inicial da primeira turma de egressos do curso de Letras/Espanhol e Literaturas EAD/UAB/UFSM, a partir dos dispositivos metodológicos e teóricos utilizados nesta pesquisa.

\section{CONSTITUIÇÃO DE COMUNIDADE: LIMITES, POSSIBILIDADES E DESAFIOS NO PERCURSO FORMATIVO EM EAD}

A partir da etapa exploratória de pesquisa foi possível alcançar dois dos objetivos específicos propostos: conhecer o perfil dos estudantes e descrever suas concepções a respeito da modalidade EAD, bem como suas relações didáticopedagógicas no âmbito do curso. Com isso, confirmou-se o típico perfil do estudante EAD: pessoas adultas que exercem atividades no mundo do trabalho e buscam uma nova formação profissional. Da mesma forma, identificou-se que a maioria dos estudantes não possuía experiência prévia na modalidade EAD e que o modo como conduziam as atividades do curso, em geral, restringia-se ao âmbito dos polos em que pertenciam.

Com a construção dos registros narrativos que emergiram nas entrevistas, os demais objetivos específicos também foram concretizados, pois foi possível então destacar os elementos que foram significativos na trajetória de formação: a adaptação processual ao AVEA do curso; a auto-aprendizagem como base da formação; a interformação - conhecimento compartilhado com os colegas; os momentos de destaque na trajetória de formação; a capacitação em formação para o uso da TIC no ensino; a 
atuação e importância da rede UAB/UFSM/Polos; a relação com os pares do percurso formativo; a trajetória formativa construída na modalidade EAD.

Esses elementos supracitados configuram características da formação de rede de formação e desenvolvimento profissional colaborativa no âmbito do curso, pois permitiram o aprofundamento maior de como esses sujeitos experienciaram este percurso formativo ao longo de quatro anos, evidenciando a construção de uma ambiência favorável à integração das TIC na formação profissional e a atuação positiva dos parceiros UAB/UFSM/Polos na trajetória de formação construída.

No entanto, os mesmos elementos, nesse contexto de formação em $\mathrm{EAD}$, não permitiram inferir a existência de fatores constitutivos de comunidade, a exemplo daqueles criados por Carvalho (2011) a partir de uma disciplina, de um curso EAD, quais sejam: (1) Reciprocidade Permanente; (2) Colaboração; (3) Compromisso Implícito; (4) Iniciativa; (5) Informalidade e (6) Intervenção pontual do educador, pois:

- Tanto na etapa exploratória, como nos registros narrativos dos sujeitos participantes da pesquisa, não se observou o estabelecimento de um contato permanente entre todos os envolvidos no curso, pois este contato ocorreu com maior ênfase entre estudantes do mesmo polo.

- Na totalidade do curso de graduação houve momentos de mais ou menos colaboração e engajamento - mas nada que se possa afirmar como recorrente para caracterizar-se como indicador.

- Como não se verificou a comunicação permanente entre os estudantes do curso, por sua vez não há indícios de um comprometimento assumido entre os pares de corresponderem-se uns com os outros. Inclusive, contrariamente, registrou-se a sensação de isolamento em partes do percurso formativo, no registro narrativo de um dos sujeitos.

- Da mesma forma, como os demais indicadores de Carvalho (2011) encontram-se fragilizados no âmbito desta pesquisa, não se pode afirmar uma predisposição individual de cada participante em contribuir com os propósitos da comunidade, pois considera-se que esta experiência formativa não foi vivenciada.

- Como este estudo não adotou como procedimento metodológico a análise da linguagem escrita no AVEA, não é possível afirmar ou não se foi utilizada uma linguagem despojada e informal, durante o percurso formativo.

- Por fim, não se pode afirmar, no contexto desta pesquisa, que a participação do educador (neste estudo representado pelo professor, tutor a distância e tutor presencial) tenha sido a nível de intervenção pontual ou de apenas supervisão. Ao contrário, os sujeitos participantes avaliaram como significativas tanto a comunicação como a relação estabelecida com os professores para a qualidade da experiência formativa.

Com certeza, no percurso formativo inicial docente investigado, o grande ganho ou avanço na trajetória de formação é a capacitação para o uso das TIC no ensino - fato que não se observava nas formações até pouco tempo, em que professores se graduavam com pouca fluência tecnológica.

As redes são metáforas muito comuns ao nosso tempo e segundo Bauman (2001) são tecidas e desmanchadas com igual facilidade, desconstituindo a possibilidade de se manter laços em longo prazo. Interligar-se é um processo mais natural, pois não nos compromete tanto como o engajamento que requer uma comunidade. 
Na mesma direção, uma rede institucionalizada, como a que se forma no contexto de um curso EAD, é uma rede em que as identidades "reais" estão expostas e por isso há uma representação da pessoa e do profissional em formação.

Contudo, a constituição de comunidade é uma experiência formativa permeada pela transitoriedade das relações humanas que são marcadas no campo da educação e, especialmente, na formação dos professores - marcada por uma série de transições de paradigmas que não consolidam, talvez, uma comunidade da área.

\section{REFERÊNCIAS}

BARDIN, Laurence. Análise de conteúdo. Lisboa: Edições 70, 1977.

BAUMAN, Zygmunt. Modernidade Líquida. Rio de Janeiro: Zahar, 2001.

. Comunidade: a Busca por Segurança no Mundo Atual. Rio de Janeiro: Jorge Zahar Ed., 2003.

CARVALHO, Jaciara de Sá. Redes e comunidades: ensino-aprendizagem pela internet. São Paulo: Editora e Livraria Instituto Paulo Freire, 2011.

GARCIA, Carlos Marcelo. Formação de professores: Para uma mudança educativa. Porto: Porto Editora, 1999.

IMBERNÓN, Francesc. Hay profesores del siglo XX, modelo escolar del XIX y alumnos del XXI. 2009. Disponível em: <http://www.diariodeibiza.es/pitiusesbalears/2009/05/01/pitises-i-balears-profesores-siglo-modelo-escolaralumnos/325387.html>. Acesso em: 8 dez. 2011.

ISAIA, Silvia Maria de Aguiar. Verbete: trajetória de formação. In: MOROSINI, M. (ed.). Enciclopédia de Pedagogia Universitária: Glossário. Vol. 2. Brasília: INEP, 2006, p. 368.

LÉVY, Pierre. A Emergência do Cyberspace e as Mutações Culturais. In.:

Ciberespaço: um hipertexto com Pierre Lévy. Nize Maria Campos Pellanda e Eduardo

Campos Pellanda (orgs.). Porto Alegre: Artes e Ofícios, 2000. p. 13-20.

MACIEL, Adriana Moreira da Rocha. Formação na docência universitária?

Realidade e possibilidades a partir do contexto da universidade de Cruz Alta. 2000. Tese (Doutorado em Educação) - Universidade Federal de Santa Maria, Santa Maria, 2000.

. Verbete: rede virtual de formação. In: MOROSINI, M. (ed.). Enciclopédia de

Pedagogia Universitária: Glossário. Vol. 2. Brasília: INEP, 2006, p. 380-81.

MORAN, José Manuel. Avaliação das mudanças que as tecnologias estão provocando na educação presencial e a distância. Educação e Cultura Contemporânea, Rio de Janeiro, v. 2, n. 4, p. 89-108, jun./dez. 2005.

PALLOFF, Rena M.; PRATT, Keith. Construindo comunidades de aprendizagem no ciberespaço: estratégias eficientes para a sala de aula on-line. Tradução Vinícius Figueira. Porto Alegre: Artmed, 2002.

RHEINGOLD, Howard. A comunidade virtual. Lisboa: Gradiva, 1996, p. 13-56.

SARAIVA, Karla. Formação de professores nas tramas da rede: uma prática de governamentalidade neoliberal. Revista Em Aberto, Brasília, v. 23, n. 84, p. 123-137, nov. 2010. 